\title{
Characterization of DNA binding activities of over- expressed KpnI restriction endonuclease and modification methylase
}

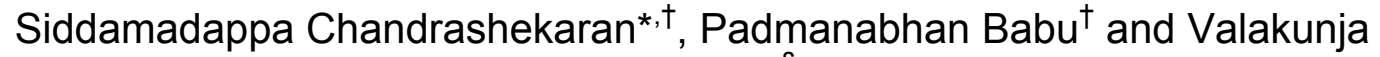 \\ Nagaraja ${ }^{* \S}$ \\ *Department of Microbiology and Cell Biology, Indian Institute of Science Bangalore 560012 , \\ India \\ ${ }^{\dagger}$ Bangalore Genei Pvt. Ltd, Industrial Suburb, Peenya, Bangalore 560 058, India \\ §Corresponding author (Fax, 91-80-3341683; Email, vraj@mcbl.iisc.ernet.in).
}

\begin{abstract}
The genes encoding the $K p n l$ restriction endonuclease and methyltransferase from Klebsiella pneumoniae have been cloned and expressed in Escherchia coli using a two plasmid strategy. The gene for $\mathrm{Kpnl}$ methylase with its promoter was cloned and expressed in PACYC184. Even though the methylase clone is in a low copy number plasmid pACMK, high level expression of methylase is achieved. A hyper-expressing clone of $K p n l$ endonuclease, pETRK was engineered by cloning the $\mathrm{R}$ gene into the $\mathrm{T7}$ expression system. This strategy resulted in over-expression of $\mathrm{Kpnl}$ endonuclease to about $15-30 \%$ of cellular protein. Both the enzymes were purified using a single chromatographic step to apparent homogeneity. The yield of purified endonuclease and methylase from one liter of culture was approximately 30 and $6 \mathrm{mg}$ respectively. Electrophoretic mobility shift assays show that both the enzymes are capable of binding to specific recognition sequence in the absence of any cofactors. The complexes of $K p n l$ methyl transferase and endonuclease with their cognate site exhibit distinctive behaviour with respect to ionic requirement.
\end{abstract}

\section{Introduction}

The primary function of restriction-modification (R-M) systems in bacteria is to serve as defense mechanisms against intruding DNA molecules (Linn and Arber 1968). R-M systems are composed of two separate enzymatic activities. One is a restriction endonuclease (Enase) that cleaves DNA at a specific recognition sequence. The second is a DNA methyltransferase (Mtase), which is able to methylate the same sequence and render it refractive to cleavage by the corresponding Enase. The Enases are defined as double-strand nucleases that recognize specific DNA sequences and cleave at a defined point within or close to that sequence. These enzymes are classified into three main groups according to their cofactor requirements and complexity of the reaction (Roberts and Halford 1993). The type II Enases require only $\mathrm{Mg}^{2+}$ as a cofactor and by far the simplest ones. Most of the enzymes of this group recognize palindromic sequence which generally vary between four to eight base pairs in length (Wilson and Murray 1991). There has been a great degree of interest to isolate and characterize new type II Enases due to their wide usage in recombinant DNA 
technology (Roberts and Macelis 1997). A number of R-M systems have been cloned, sequenced and hyper-expressed primarily because of their application potential and commercial benefits. The cloning methods are generally based on bacteriophage infection (Mann et al 1978; Walder et al 1981), Mtase selection (Kiss et al 1985), induction of the DNA-damage inducible SOS response by the $m c r$ and $m r r$ systems, in the presence of methylated DNA (Piekarowicz et al 1991) and transferring the plasmid encoding R-M genes into Escherichia coli cloning vectors (Bougueleret et al 1984; Gingeras and Brooks 1983; Blumenthal et al 1985). Although recognition sequences for a large number of Enases are known, less information is available on their structure-function relationship and biochemical properties. By virtue of their remarkable sequence specificity, they also serve as very good model systems for studying protein-DNA interactions.

Sequence comparison of $\mathrm{R}$ genes has revealed surprising results. Very little sequence conservation is observed amongst Enases except few residues involved in catalysis. In contrast, distinct motifs are found representing characteristic patterns of different sub-classes viz., $\mathrm{N}^{6}$ adenine, $\mathrm{N}^{4}$ cytosine or $\mathrm{C}^{5}$ cytosine Mtases (Posfai et al 1989; Kumar et al 1994). Another noteworthy feature is the absence of any sequence similarity between Mtases and cognate Enases. Thus, Enases and the corresponding Mtases constitute a unique class of DNA binding proteins which recognize same sequence, yet catalyze totally different type of enzymatic reactions. Delineation of molecular interaction parameters of the two non-homologous proteins which recognize same sequence would constitute an important study in the area of nucleic acid-protein interactions. In this direction, we have over-expressed Kpnl Enase and Mtase genes and studied the DNA binding properties of the purified enzymes.

\section{Materials and methods}

\subsection{Bacterial strains and plasmids}

Klebsiella pneumoniae strain (ATCC 4970) was used for cloning Kpnl R-M system. E.coli DH10B [mcrAD ( $m r r$ hsd RMS mcrBC) endA1 f 80 dlacZ D M15 D lac X74 recA1 deoRD (ara, leu) 7697ara D139 galU galK nupG rpsL] and plasmids pACYC184 (cam ${ }^{R}+$ tet $\left.^{R}\right)$ (Chang and Cohen 1978) and pTrc99C $\left(a m p^{R}\right.$ ) (Amann et al 1988) were from our laboratory collection. pET11d was obtained from Novagen. K. pneumoniae and other E. coli strains were grown in Luria Bertani (LB) medium.

\subsection{Enzymes and chemicals}

Restriction enzymes, T4 DNA ligase, Klenow polymerase, Taq DNA polymerase, T4 polynucleotide kinase, oligonucleotides, deoxynucleotidetriphosphates and IPTG were obtained from Bangalore Genei Pvt. Ltd. Shrimp alkaline 
phosphatase, [methyl- $\left.{ }^{3} \mathrm{H}\right]-\mathrm{S}$-adenosyl-L-methionine $\left(\left[\mathrm{H}^{3}\right]\right.$ AdoMet $)$ and [g ${ }^{32}$ PJATP were purchased from Amersham.

\subsection{DNA preparation}

Total chromosomal DNA was isolated from $K$. pneumoniae cells by SDSproteinase K lysis followed by phenol-chloroform extraction (Ausubel et al 1987). Small and large scale plasmid isolations were done by alkaline-lysis method (Sambrook et al 1993).

\subsection{PCR amplification of Mtase and Enase genes}

All PCR reactions were performed using GeneAmp PCR System (Perkin Elmer). $\mathrm{kpniM}$ (Kpnl methylase) gene was amplified as a $1.3 \mathrm{~kb}$ fragment using a forward primer which has a Stul site and a reverse primer which carries a Hindlll site (table 1, primers 1 and 2). The reaction mixture contained $10 \mathrm{mM}$ TAPS (3-tris[ hydroxy methyl] aminopropane sulphonic acid) $\mathrm{pH} 8 \cdot 8,50 \mathrm{mM}$ potassium chloride, $1.5 \mathrm{mM}$ magnesium chloride, $0.01 \%$ gelatin, $200 \mathrm{~m} \mathrm{M}$ deoxynucleotidetriphosphates, 1.5 units of Taq DNA polymerase, $100 \mathrm{ng}$ of $K$. pneumoniae genomic DNA and $0.25 \mathrm{~m} \mathrm{~g}$ each of the forward and reverse primers. kpniR ( $K p n l$ endonuclease) gene was amplified as a $0.7 \mathrm{~kb}$ fragment using two primers which carry $\mathrm{Ncol}$ and $\mathrm{BamHI}$ sites (table 1, primers 3 and 4).

\subsection{Expression of Kpnl Enase and Mtase}

E. coli cells harbouring the Mtase clone pACMK were grown for $12-16 \mathrm{~h}$ at $37^{\circ} \mathrm{C}$ and harvested by centrifugation for $10 \mathrm{~min}$ at $10,000 \mathrm{~g}$. E. coli containing cloned $k p n i R$ gene in the presence of pACMK was grown in LB medium containing $100 \mathrm{~m} \mathrm{~g} / \mathrm{ml}$ ampicillin and $20 \mathrm{~m} \mathrm{~g} / \mathrm{ml}$ chloramphenicol at $37^{\circ} \mathrm{C}$ until the absorbance at $600 \mathrm{~nm}$ reached $0 \cdot 6$. Then the cells were induced with $1 \mathrm{mM} \mathrm{IPTG}$ $(0.3 \mathrm{mM}$ IPTG in the case of pETRK clone) and harvested after $3 \mathrm{~h}$ incubation at $37^{\circ} \mathrm{C}$ by centrifugation for $10 \mathrm{~min}$ at $10,000 \mathrm{~g}$. Protein samples were analysed by SDS-PAGE as described by Laemmli (1970).

\subsection{Detection of Mtase activity}

The chromosomal DNA was isolated and purified from E. coli carrying the plasmid for Mtase gene. One $\mathrm{m} \mathrm{g}$ of the chromosomal DNA was incubated with excess of $K p n l$ Enase for $2 \mathrm{~h}$ at $37^{\circ} \mathrm{C}$ to check the cleavage. The enzyme was also assayed by transfer of methyl group from AdoMet to the substrate DNA. The assay reaction contained $50 \mathrm{mM}$ Tris- $\mathrm{HCl}(\mathrm{pH} 7 \cdot 4), 5 \mathrm{mM}$ EDTA, $5 \mathrm{mM}$ b mercaptoethanol, $100 \mathrm{~m} \mathrm{~g} / \mathrm{ml} \mathrm{BSA}, 1.5 \mathrm{~m} \mathrm{~g}$ of I DNA, $0.1 \mathrm{~m} \mathrm{Ci}$ of [methyl- ${ }^{3} \mathrm{H}$ ] AdoMet (sp.activity, $263 \mathrm{Beq} / \mathrm{mmol}$ ) and different amounts of enzyme in a $20 \mathrm{~m} \mathrm{I}$ reaction mixture. The reactants were incubated at $37^{\circ} \mathrm{C}$ for $30 \mathrm{~min}$ and $5 \mathrm{~m} \mathrm{I}$ of the mixture was taken onto a GF/C filter, dried, washed with $10 \%$ TCA and acid precipitable counts measured using liquid scintillation counter. 


\subsection{Detection of Enase activity in vitro}

An induced culture $(100 \mathrm{ml})$ was prepared and the cells were harvested by centrifugation for $10 \mathrm{~min}$ at $10,000 \mathrm{~g}$. The pellet was resuspended in $10 \mathrm{ml}$ of $10 \mathrm{mM}$ Tris- $\mathrm{HCl}(\mathrm{pH} 7 \cdot 4), 0 \cdot 1 \mathrm{mM}$ EDTA, $7 \mathrm{mM}$ b -mercaptoethanol and $2 \mathrm{mM}$ phenyl methyl sulphonyl fluoride (PMSF) and lysed by sonication for 5 min. A crude extract was prepared by centrifugation of the sonicated sample for $30 \mathrm{~min}$ at 20,000. Different concentrations of the extract were incubated with $1 \mathrm{~m} \mathrm{~g}$ of I DNA in $50 \mathrm{~m}$ I reaction mixture containing $10 \mathrm{mM}$ Tris- $\mathrm{HCl}(\mathrm{pH} 7 \cdot 4), 10 \mathrm{mM}$ magnesium chloride and $5 \mathrm{mM} \mathrm{b}$-mercaptoethanol at $37^{\circ} \mathrm{C}$ for $1 \mathrm{~h}$. The reactions were terminated by adding $5 \mathrm{~m}$ I stop buffer [20\% Ficoll, $50 \mathrm{mM}$ EDTA, bromophenol blue $(0 \cdot 1 \%)$ xylene cyanol $(0.1 \%)]$ and then resolved by electrophoresis for 1 to $2 \mathrm{~h}$ at $100 \mathrm{~V}$ on $0.8 \%$ agarose gels in $40 \mathrm{mM}$ Tris-acetate $(\mathrm{pH} 7.8), 1 \mathrm{mM}$ EDTA, $0.5 \mathrm{~m} \mathrm{~g} / \mathrm{ml}$ ethidium bromide. The unit for the enzyme activity was estimated by incubating various amounts of enzyme with $1 \mathrm{~m} \mathrm{~g}$ of I DNA under the standard assay conditions. One unit of the Kpnl Enase is defined as the amount of enzyme required to digest $1 \mathrm{~m} \mathrm{~g}$ of I DNA.

\subsection{Purification of Kpnl Enase and Mtase}

For the purification of Enase, $4 \mathrm{~g}$ of cells were resuspended in $15 \mathrm{ml}$ of buffer $\mathrm{A}$ [10 mM potassium phosphate (pH 7.0), $1 \mathrm{mM}$ EDTA, $7 \mathrm{mM}$ b -mercaptoethanol] with $2 \mathrm{mM}$ PMSF. Cells were lysed by sonication for $30 \mathrm{~min}$ and centrifuged at $100,000 \mathrm{~g}$ for $2 \mathrm{~h}$. The supernatant was treated with $1 \%$ polyethyleneimine (PEI) in the presence of $250 \mathrm{mM} \mathrm{KCl}$. The sample was centrifuged at $20,000 \mathrm{~g}$ for $15 \mathrm{~min}$ and the supernatant was subjected from 0 to $50 \%$ ammonium sulphate fractionation. The pellet was dissolved in $5 \mathrm{ml}$ of buffer $\mathrm{A}$ and dialyzed against buffer $\mathrm{A}$. The dialyzed sample was loaded onto a $5 \mathrm{ml} \mathrm{Hi-Trap} \mathrm{heparin} \mathrm{column}$ and the enzyme was eluted with buffer A containing $0-0.8 \mathrm{M} \mathrm{KCl}$. The fractions containing the enzyme (between $200-350 \mathrm{mM} \mathrm{KCl}$ ) were pooled and dialyzed against buffer $\mathrm{B}$ [10 mM Tris- $\mathrm{HCl}(\mathrm{pH} 7 \cdot 4), 0 \cdot 1 \mathrm{mM}$ EDTA, $50 \mathrm{mM} \mathrm{KCl}, 5 \mathrm{mM} \mathrm{b}$ mercaptoethanol and $50 \%$ glycerol]. The protein estimation was done by dye binding method using bovine serum albumin as standard (Bradford 1976).

The Kpnl Mtase was purified from $10 \mathrm{~g}$ of overnight grown cells. The cells were sonicated with $20 \mathrm{ml}$ of buffer A containing $2 \mathrm{mM}$ PMSF and centrifuged at $100,000 \mathrm{~g}$ for $2 \mathrm{~h}$. The crude extract was treated with $1 \% \mathrm{PEI}$ in the presence of $250 \mathrm{mM} \mathrm{KCl}$. The sample was centrifuged and the supernatant was subjected to $0-30 \%$ ammonium sulphate fractionation. The pellet was dissolved in a $5 \mathrm{ml}$ of buffer A, dialyzed and was loaded onto a $5 \mathrm{ml}$ heparin column and eluted with 0 $1 \mathrm{M} \mathrm{KCl}$. The fractions containing the enzyme (between 0.65-0.9 M KCl) were pooled and dialyzed against buffer $\mathrm{B}$ [10 mM Tris-HCl (pH 7.4), $0.1 \mathrm{mM}$ EDTA, $50 \mathrm{mM} \mathrm{KCl}, 5 \mathrm{mM} \mathrm{b}$-mercaptoethanol and $50 \%$ glycerol]. 


\subsection{Electrophoretic mobility shift assay}

The substrate used for DNA binding assays was a 38 mer double stranded oligonucleotide which contains $\mathrm{Kpnl}$ site at the middle (table 1 , primers 5 and 6 ).

One of the strands was labelled using T4 polynucleotide kinase and [ $\left.\mathrm{g}-{ }^{32} \mathrm{P}\right]$ ATP (sp. activity, $5000 \mathrm{Ci} / \mathrm{mmol}$ ). The two strands were annealed by heating the sample to $80^{\circ} \mathrm{C}$ and then cooling to room temperature slowly. The protein-DNA complexes were formed by incubation of the enzyme with $10 \mathrm{nM}$ labelled double stranded oligonucleotide containing Tris- $\mathrm{HCl}(\mathrm{pH} 7 \cdot 4), 5$ mM EDTA, $7 \mathrm{mM}$ 2mercaptoethanol and different concentrations of either Kpnl Mtase or Enase $(2 \mathrm{nM}-500 \mathrm{nM})$. The reaction mixture was incubated at room temperature for $15 \mathrm{~min}$ followed by the addition of $2 \mathrm{~m}$ I of stop buffer [ $20 \%$ Ficoll, $50 \mathrm{mM}$ EDTA, bromophenol blue $(0 \cdot 1 \%)$ xylene cyanol $(0 \cdot 1 \%)]$. The samples were then loaded on to $6 \%$ (or $8 \%$ ) native acrylamide gel $(30: 0 \cdot 8)$ and electrophoresed using $1 \times$ TBE $(\mathrm{pH} 8.3)$ or with $50 \mathrm{mM}$ HEPES (pH 7.4) and $2 \mathrm{mM}$ EDTA at a constant voltage of $10 \mathrm{~V} / \mathrm{cm}$ for $1 \mathrm{~h}$ at $4^{\circ} \mathrm{C}$. The complexes were detected by autoradiography of the dried gel.

\section{Results}

\subsection{Organization of regulatory elements in Kpnl R-M systems}

The genes for Kpnl Enase and Mtase are present within the close proximity to each other in K. pneumoniae genome (Chatterjee et al 1991). Kpnl Enase recogni-zes and cleaves the DNA sequence $5 \phi-$ GGTAC $^{-}$C-3 $\phi$ (Hammond et al 1990). The Kpnl Mtase recognizes the same sequence and methylates adenine residue at $\mathrm{N}^{6}$ position (Kiss et al 1991). Like other R-M systems, the Kpnl Enase and Mtase open reading frames (ORFs) do not show any considerable sequence similarity inspite of recognizing the same sequence element. The gene organization and promoter elements for $K p n l \mathrm{R}-\mathrm{M}$ system is depicted in the figure 1 . The $R$ and $M$ genes are arranged divergently and separated by $167 \mathrm{bp}$. The intergenic region contains all the regulatory elements required for the expression of both the genes. The promoters are separated by $57 \mathrm{bp}$ and present in opposite strands having typical characteristic features of s -70 promoters of E. coli (Hawley and McClure 1983; Nagaraja 1993). Moreover codon usage pattern of both Mtase and Enase ORFs is similar to that of $E$. coli. These characteristics suggest that expressing functional proteins of Kpnl R-M system in E. coli is feasible.

\subsection{Strategy employed for cloning}

Further analysis of promoter elements of Kpnl Enase and Mtase (figure 1) suggest that their relative strengths could vary to a significant extent. The Mtase promoter appeared to be stronger having six out of six nucleotide consensus at - 
10 sequence $(5 \phi-$ TATAAT- $3 \phi)$ and four out of six to the -35 consensus sequence $(5 \phi-$ TTGACA- $3 \phi)$. In contrast, only three and four nucleotides out of six consensus sequence found in -10 and -35 elements respectively in the case of $K p n l$ Enase (figure 1). Thus, the strategy for cloning the genes involved, prior cloning of the Mtase gene with its own promoter sequences in a low copy number plasmid. This would allow sufficient over-expression of Mtase to ensure complete protection of the genomic DNA when gene for cognate Enase is cloned into the strain containing the cloned Mtase gene. The kpniR gene cloning however, would be as a promoter-less fragment downstream of a strong trc or T7 promoter to ensure very high level expression.

\subsection{Kpnl Mtase hyper-expression and purification}

The kpniM gene amplified with its own promoter elements was cloned into pACYC184 (figure 2A). The introduction of the gene between EcoRV and HindlII sites results in the inactivation of tet gene and also constitutive expression of the Mtase. The expression of functional Mtase is assayed by the resistance to $\mathrm{Kpnl}$ cleavage of the DNA isolated from the cells harbouring Mtase plasmid. The enzyme activity was directly assayed by transfer of methyl group to substrate DNA using $\left[{ }^{3} \mathrm{H}\right]$-labelled AdoMet ( $\S 2$ ). The expression of Mtase was monitored by analysing the protein samples in SDS-PAGE at different time intervals during the growth (not shown). Over-night cultures (12-16 h) of the pACMK containing cells showed considerable over-production of the Mtase (figure 2B). The overexpressed Kpnl Mtase has relative molecular mass of $44 \mathrm{kDa}$ corresponding the size derived from its ORF. Using the pACMK clone, the Kpnl Mtase was purified by facile purification procedure involving single chromatography step $(\S 2$, figure $2 \mathrm{C}$ ). From one liter of the culture, $6 \mathrm{mg}$ of purified protein was obtained.

\subsection{Kpnl Enase hyper-expression and purification}


In contrast to $\mathrm{Kpnl}$ methylase cloning, Enase gene was cloned as a promoterless fragment into two separate expression vectors. The cloning strategy of the PCR product into $\mathrm{pTrc99C}$ and pET11d is shown in figure 3A. While both the systems are inducible by IPTG, the former is driven by trc- a trp-lac hybrid promoter (Amann et al 1988) while latter is driven by T7 RNA polymerase-T7 promoter system (Studier and Moffatt 1986). Although the inducible trc promoter is expected to produce large amounts of protein, the pTrcRK construct did not show high level of expression (see discussion). The total Kpnl Enase activity in this clone was about $10^{7}$ units per 1 litre culture which is only 20 times more than that obtained from the wild type strain. This prompted us to pursue the alternate approach of using T7 expression system to obtain high levels of expression. The cloned genes from this expression system are expressed from a strong T7 promoter. Further, the presence of lacl gene ensures efficient repression of the basal transcription levels. The time course of IPTG induction using pETRK clone is shown in figure 3B. Most of the protein was expressed within 2-3 h after the induction. The protein has approximate molecular mass of $32 \mathrm{kDa}$. Analysis of the protein profile from the pellet and supernatant fractions of the lysed cells showed that the most of the protein was in the latter fraction (not shown). The enzyme has been purified to near homogeneity using heparin sepharose chromatography (figure $3 \mathrm{C}$ ). The total activity estimated from this clone was at least $2^{\prime} 10^{8}$ units per 1 litre culture which approximately corresponds to the specific activity $>2^{\prime} 10^{6}$ units/mg with I DNA as a substrate. The specific activity is comparable to that of other type II Enases having hexameric recognition sequences (Maxwell and Halford 1982; Theriault et al 1985; Brooks et al 1989).

\subsection{Analysis of enzyme-DNA complexes}

The purified Kpnl Enase and Mtase were used to probe their interaction with specific recognition sequence in electrophoretic mobility shift assays. For this purpose a 38 mer duplex oligonucleotide was designed having $5 \phi-$ GGTACC-3 $\not \phi$ sequence at the centre. A single Kpnl Enase enzyme-DNA complex is detected when the enzyme is incubated with substrate oligonucleotide (figure 4A); the protein-DNA complex was not observed when the protein was incubated with 38 mer duplex DNA which does not contain the Kpnl site (not shown) indicating that the complex was specific to Kpnl Enase. The enzyme-DNA complex was formed over a broad pH range of $6.5,7 \cdot 4$ and 8.3 (not shown). The effect of monovalent cation, such as $\mathrm{Na}^{+}$was studied on the complex formation. The interaction was salt sensitive as complex formation was observed only between 0 to $75 \mathrm{mM} \mathrm{NaCl}$ concentrations. Beyond this concentration of $\mathrm{NaCl}$, detectable enzyme-DNA complex was not observed (figure 4B). The binding was maximum in the absence of salt or very low $\mathrm{NaCl}$ concentrations. This is in agreement with cleavage characteristics of the enzyme; maximum cleavage activity was obtained with buffers having low ionic strength. Addition of $5 \mathrm{mM} \mathrm{Mg}{ }^{2+}$ to DNA-protein complex produced dramatic 
change in the interaction pattern. Instead of the slower moving complex (figure $4 \mathrm{C}$, panel $\mathrm{B}$, lane 1 ), a faster moving cleavage product (lane 2 and 3 ) appears, as $\mathrm{Mg}^{2+}$ is a cofactor for the enzymatic reaction. The enzyme cleaves the DNA in the presence of $\mathrm{Mg}^{2+}$ even at $4^{\circ} \mathrm{C}$ (figure $4 \mathrm{~B}$, panel $\mathrm{B}$, lane 2). These results taken together reflect high degree of specific interaction of the enzyme with the substrate prior to the addition of cofactor.

Incubation of $K p n l$ Mtase with the same 38 mer substrate DNA leads to the formation of DNA-protein complex (figure 5). In contrast to Enase-DNA complex, the Mtase-DNA complex is resistant to different concentrations of monovalent cation; complex was detected at $300 \mathrm{mM} \mathrm{NaCl}$ concentration (figure 5, lane 8). DNA-protein complex was observed in absence of S-adenosine homocysteine (AdoHcy) unlike many other Mtases (figure 5, lane 1). The presence of AdoHcy did not influence the complex formation to a great extent (figure 5, lane 3).

\section{Discussion}

In this paper, we describe the cloning and over-expression of R-M system from $K$. pneumoniae. Further we show that DNA binding properties of the purified proteins exhibit certain distinctive characteristics.

One major objective of this study was to express large amounts of Kpnl Enase and its cognate Mtase for detailed biochemical and structural analysis. Thus, the strategy involved cloning of kpniR gene from the genomic DNA into suitable expression vectors and transform into cells which were already harbouring the Mtase plasmid. Prior expression of Mtase would ensure stable maintenance and expression of $\mathrm{R}$ gene. Although Mtase was cloned into a low copy number vector, high level expression was achieved. This is possibly due to the presence of promoter elements bearing resemblance to strong promoters and perfect Shine-Dalgarno sequence apart from other features appropriate for overexpression in E. coli (Makrides 1996). Further, there seems to be continued accumulation of the enzyme when the cells were grown over long periods of time. The hyper-expression and the convenient purification of functional Mtase would facilitate the purification of the enzyme in large scale for structural studies. Inspite of high level expression, the Kpnl Enase is completely soluble. This is some what unexpected as high level expression in E. coli using T7 expression system often leads to inclusion bodies which is a frequently encountered problem. One possible explanation for high solubility of Kpnl Enase is similar codon usage in both K. pneumoniae and $E$. coli, thus minimizing the mistranslation products. The hyper-expression of Kpnl Enase would facilitate the purification of the protein in large quantities. This would enable studies on structure function relationships, solution structure analysis and detailed proteinDNA interaction studies. Several major efforts are underway to determine the 
solution structures of Enases. The structural information is available for EcoRI (Kim et al 1990), EcoRV (Winkler et al 1993; Winkler 1992), BamHI (Newman et al 1994), Pvull (Cheng et al 1994), Cfr10l (Bozic et al 1996), Fokl (Wah et al 1997 ) and Bgll (Newman et al 1998). While these enzymes have distinct structures, a notable common feature seems to be the organization of conserved catalytic sequence motifs (PD and D/EXK-) at the reaction centre (Stahl et al 1998).

As a prelude to detailed structural analysis, we have assessed the complex formation of Kpnl Mtase and Enase with DNA substrate having the recognition sequence. Kpnl Enase forms stable complex with 38 mer specific duplex oligonucleotide in the absence any cofactor. In the presence of magnesium there was a cleavage product seen even at $4^{\circ} \mathrm{C}$. The absence of complex formation with a non-specific 38 mer duplex oligonucleotide indicates that the enzyme readily discriminates between specific and non-specific sites unlike in the case of EcoRV, Taql and Cfr9l where the specificity is brought about by magnesium ion (Taylor et al 1991; Zebala et al 1992; Siksnys and Pieckkaityte 1993). Kpnl Enase forms specific complex at broad pH values $6 \cdot 5,7 \cdot 4$ and $8 \cdot 3$ (not shown). In contrast, Munl Enase does not exhibit specific binding at $\mathrm{pH} 8 \cdot 5$, but shows considerable sequence specificity at pH 6.5 (Lagunavicius et al 1997). EcoRV also exhibits $\mathrm{pH}$ dependent variation in sequence specific interaction at its recognition sequence (Engler et al 1997). In the case of Mtases, addition of cofactor or competitive inhibitor to the binding reaction is known to facilitate the formation of specific enzyme-DNA complex (Dubey and Roberts 1992; Chen et al 1991; Wyszynski et al 1993). Kpnl Mtase, however, forms specific complex in the absence AdoHcy (figure 5). A notable feature is the formation of Kpnl MtaseDNA complex even at high concentrations of monovalent cations. In contrast, ionic interactions do not seem to contribute in a significant manner for the formation of specific DNA-Enase complex. Thus, the complexes of these enzymes with DNA respond in very different manner to the ionic environment. If these contrasting features in DNA recognition by the two enzymes could be considered as pointers of their differential interaction, a detailed analysis should unravel the molecular secrets of specificity determination in target recognition.

\section{Acknowledgements}

We thank J Babu for discussions, S Srinivasan for technical help and S Mahadevan, D R Radha and M V Hema for FPLC purification. Financial support for this work has been obtained from the Technology Development Mission, New Delhi and Bangalore Genei Pvt. Ltd., Bangalore.

\section{References}


Amann E, Ochs B and Abel K J 1988 Tightly regulated tac promoter vectors useful for the expression of unfused and fused proteins in Escherichia coli; Gene $69301-315$

Ausubel F M, Brent R, Kingston R E, Moore D D, Seidman J G, Smith J A and Struhl K 1987 Current protocols in molecular biology (New York: John Wiley)

Blumenthal R M, Gregory S A and Cooperider J S 1985 Cloning of a restrictionmodification system from Proteus vulgaris and its use in analyzing a methylsensitive phenotype in Escherichia coli; J. Bacteriol. 164 501-509

Bougueleret L, Schwarzstein M, Tsugita A and Zabeau M 1984 Characterization of the genes coding for the EcoRV restriction and modification system of Escherichia coli; Nucleic Acids Res. 12 3659-3676

Bozic D, Grazulis S, Siksnys V and Huber R 1996 Crystal structure of Citrobacter freundii restriction endonuclease Cfr10l at 2.15 Å resolution; J. Mol. Biol. 255 176-186

Bradford M M 1976 A rapid and sensitive method for the quantitation of microgram quantities of protein utilising the principle of protein-dye binding; Anal. Biochem. 72 248-254

Brooks J E, Benner J S, Heiter D F, Silber K R, Sznyter L A, Jager-Quinton T, Moran L S, Slatko B E, Wilson G G and Nwankwo D O 1989 Cloning the BamHI restriction modification system; Nucleic Acids Res. 17 979-997

Chang A C Y and Cohen S N 1978 Construction and characterization of amplifiable Multicopy DNA cloning vehicles derived from the p15A cryptic miniplasmid; J. Bacteriol. 134 1141-1156

Chen L, MacMillan A M, Chang W, Ezaz-Nikpay K, Lane W S and Verdine G L 1991 Direct identification of the activesite nucleophile in a DNA (Cytosine-5)-methyltransferase; Biochemistry 30 11018-11025

Cheng X, Balendiran K, Schildkraut I and Anderson J E 1994 Structure of Pvull endonuclease with cognate DNA; EMBO J. 13 3927-3935

Chatterjee D K, Hammond A W, Blakesley R W, Adams S M and Gerard G F 1991 Genetic organization of Kpnl restriction and modification system; Nucleic Acids Res. 19 6505-6509

Dubey A K and Roberts R J 1992 Sequence specific DNA binding by the Mspl methyltransferase; Nucleic Acids Res. 20 3167-3173

Gingeras T R and Brooks J E 1983 Cloned restriction/modification system from Pseudomonas aeroginosa; Proc. Natl. Acad. Sci. USA 80 402-406

Engler L E, Welch K K and Jen-Jocobson L 1997 Specific binding by EcoRV endonuclease to its cognate recognition site GATATC; J. Mol. Biol. 269 82-101 
Hammond A W, Gerard G F and Chatterjee D K 1990 Cloning the Kpnl restriction-modification system in Escherichia coli; Gene 97 97-102

Hawley D K and McClure W R 1983 Compilation and analysis of Escherichia coli promoter sequences; Nucleic Acids Res. 11 2237-2255

Kim Y, Grable J C, Choi P J, Greene P and Rosenberg J M 1990 Refinement of EcoRI endonuclease crystal structure: a revised protein chain chasing; Science 249 1307-1309

Kiss A, Kinta C and Venetianer P 1991 M.Kpnl is an adenine-methyltransferase; Nucleic Acids Res. 193460

Kiss A, Posfai G, Keller C C, Venetianer P and Roberts R J 1985 Nucleotide sequence of BsuRI restriction-modification system; Nucleic Acids Res. 136403 6421

Kumar S, Cheng X, Klimasauskas S, Mi S, Posfai J, Roberts R J and Wilson G G 1994 The DNA (cytosine-5) methyltransferases; Nucleic Acids Res. 22 1-10

Laemmli U K 1970 Cleavage of structural proteins during the assembly of the head of bacteriophage T4; Nature (London) 227 680-685

Lagunavicius A, Grajulis S, Balciunaite E, Vainius D and Siksnys V 1997 DNA binding specificity of Munl restriction endonuclease is controlled by $\mathrm{pH}$ and calcium ions: involvement of active site carboxylate residues; Biochemistry 37 11093-11099

Linn S and Arber W 1968 Host specificity of DNA produced by Escherichia coli, $X$. In vitro restriction of phage FD replicative form; Proc. Natl. Acad. Sci. USA 59 $1300-1309$

Makrides S C 1996 Strategies for achieving high-level expression of genes in Escherichia coli; Microbiol. Rev. 60 512-538

Mann M B, Rao R N and Smith H O 1978 Cloning of restriction and modification genes in Escherichia coli. The Hhall system from Haemophilus haemolyticus; Gene 3 97- 112

Maxwell A and Halford S E 1982 The Sa/GI restriction endonuclease. Purification and properties; Biochem. J. 23 77-84

Nagaraja V 1993 Control of transcription initiation; J. Biosci. 18 13-25

Newman M, Strzeleckka T, Dorner L F, Schildkraut I and Aggarwal A K 1994 Structure of BamHI endonuclease bound to DNA: partial folding and unfolding on DNA binding; Science 269 656-663

Newman M, Lunnen K, Wilson G, Greci J, Schildkraut I and Philips S E 1998 Crystal sturucture of restriction endonuclease $B g / l$ bound to its inerrupted DNA recognition sequence; EMBO J. 17 5466-5476 
Piekarowicz A, Yuan R and Stein D C 1991 A new method for the rapid identification of genes encoding restriction and modification enzymes; Nucleic Acids Res. 19 1831-1835

Posfai J, Bhagwat A S, Posfai G and Roberts R J 1989 Predictive motifs derived from cytosine methyltransferases; Nucleic Acids Res. 17 2421-2435

Roberts R J and Halford S E 1993 Type II restriction enzymes; in Nucleases (eds) S M Linn, R S Lloyd and R J Roberts (New York: Cold Spring Harbor Laboratory Press) pp 35-88

Roberts R J and Macelis D 1997 REBASE-restriction enzymes and methylases; Nucleic Acids Res. 25 248-262

Sambrook J, Fritsch E F and Maniatis T 1993 Molecular cloning. A laboratory manual 2nd edition (NewYork: Cold Spring Harbor Laboratory Press)

Siksnys V and Pieckkaityte M 1993 Catalytic and binding properties of restriction endonuclease Cfr9l; Eur. J. Biochem. 217 411-419

Stahl F, Wende W, Jeltsch A and Pingoud A 1998 The mechanism of DNA cleavage by the type II restriction enzyme EcoRV: Asp36 is not directly involved in DNA cleavage but serves to couple indirect readout to catalysis; Biol. Chem. 379 467- 473

Studier F W and Moffatt B A 1986 Use of bacteriophage T7 RNA polymerase to direct selective high-level expression of cloned genes; J. Mol. Biol. 189 113-130

Theriault G, Roy P H, Howard K A, Benner J S, Brooks J E, Waters A F and Gingeras T R 1985 Nucleotide sequence of the PaeR7 restriction modification system and partial characterization of its protein products; Nucleic Acids Res. 13 $8441-8461$

Taylor J D, Badcoe I G, Clarke A R and Halford S E 1991 EcoRV restriction endonuclease binds all DNA sequences with equal affinity; Biochemistry 30 8743-8753

Wah D A, Hirsch J A, Dorner L F, Schildkraut I and Aggarwal A K 1997 Structure of the multimodular endonuclease Fokl bound to DNA; Nature (London) 388 97100

Walder R Y, Hartley J L, Donelson J E and Walder J A 1981 Cloning and expression of the Pstl restriction-modification system in Escherichia coli; Proc. Natl. Acad. Sci. USA 78 1503-1507

Wilson G G and Murray N E 1991 Restriction and modification systems; Annu. Rev. Genet. 25 585-627

Winkler F K 1992 Structure and function of restriction endonucleases; Curr. Opin. Struc. Biol. 2 93-99

Winkler F K, Banner D W, Oefner C, Tsernoglou D, Brown R S, Heathman S P, Bryan R K, Martin P D, Petratos K and Wilson K S 1993 The 
crystal structure of EcoRV endonuclease and of its complexes with cognate and non-cognate DNA fragments; EMBO J. 12 1781-1795

Wyszynski M W, Gabbara S, Kubareva E A, Romanova E A, Oretskaya T S, Gromova E S, Shabarova Z A and Bhagwat

A S 1993 The systeine conserved among DNA cytisine methylases is required for methyl transfer, but not for specific DNA binding; Nucleic Acids Res. 21 295301

Zebala J A, Choi J and Barany F 1992 Characterization of steady state, single turnover and binding kinetics of the Taql; J. Biol. Chem. 267 8097-8105

MS received 9 March 1999; accepted 11May 1999

Corresponding editor: Seyed E Hasnain

BACK TO CONTENTS 